\title{
Morphology informed by phylogeny reveals unexpected patterns of species differentiation in the aquatic moss Rhynchostegium riparioides s.l.
}

\author{
Virginie Hutsemékers ${ }^{\mathrm{a}, *}$, Cristiana C. Vieira ${ }^{\mathrm{b}}$, Rosa María Ros ${ }^{\mathrm{c}}$, Sanna Huttunen ${ }^{\mathrm{d}}$, Alain Vanderpoorten ${ }^{\mathrm{a}}$ \\ a Université de Liège, Institut de Botanique, B22 Sart Tilman, B-4000 Liège 1, Belgium \\ ${ }^{\mathrm{b}}$ Universidade do Porto, Departamento de Biologia, Edificio FC4, 4169-007 Porto, Portugal

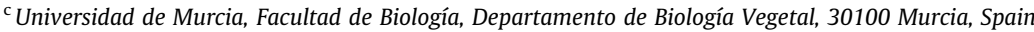 \\ ${ }^{\mathrm{d}}$ University of Turku, Dept. of Biology, Laboratory of Genetics, 20014 Turku, Finland
}

\section{A R T I C L E I N F O}

\section{Article history:}

Received 31 August 2011

Revised 8 November 2011

Accepted 17 November 2011

Available online 25 November 2011

\section{Keywords:}

Linnean shortfall

Moss

Macaronesia

Rhynchostegium

Phylogeny

Morphology

\begin{abstract}
A B S T R A C T
Bryophyte floras typically exhibit extremely low levels of endemism. The interpretation, that this might reflect taxonomic shortcomings, is tested here for the Macaronesian flora, using the moss species complex of Rhynchostegium riparioides as a model. The deep polyphyly of $R$. riparioides across its distribution range reveals active differentiation that better corresponds to geographic than morphological differences. Morphometric analyses are, in fact, blurred by a size gradient that accounts for $80 \%$ of the variation observed among gametophytic traits. The lack of endemic diversification observed in $R$. riparioides in Macaronesia weakens the idea that the low rates of endemism observed in the Macaronesian bryophyte flora might solely be explained by taxonomic shortcomings. To the reverse, the striking polyphyly of North American and European lineages of $R$. riparioides suggests that the similarity between the floras of these continents has been over-emphasized. Discriminant analyses point to the existence of morphological discontinuities among the lineages resolved by the molecular phylogeny. The global rate of error associated to species identification based on morphology $(0.23)$ indicates, however, that intergradation of shape and size characters among species in the group challenges their identification.
\end{abstract}

(C) 2011 Elsevier Inc. All rights reserved.

\section{Introduction}

About $1 / 10$ of the world's species have been described to date (Wilson, 2003), and the gap between formally described and cataloged species, and species that remain to be discovered, has been termed the Linnean shortfall (Brown and Lomolino, 1998). As techniques for examining biological diversity in all forms, and in particular, molecular data, have become more widely used and accessible, the speed at which new taxa have been discovered (but not necessarily described, see Oliver and Lee, 2010), has substantially increased (see Bickford et al., 2007 for a review). Numerous patterns of diversity are, in fact, not necessarily reflected by the morphology of organisms (Egge and Simons, 2006), suggesting that morphological characters provide a very broad species concept that does not reflect the true extent of evolutionary divergence and reproductive isolation (Harper et al., 2009; Pavlic et al., 2009; Samson and Varga, 2009). This might have substantial consequences for our understanding of biogeographic patterns of biodiversity. For example, studies based on the analysis of distribution data from checklists found that the flora of the Azores differs from other island floras in the exceptionally low number of radiations and the low

\footnotetext{
* Corresponding author. Fax: +32 43662925.

E-mail address: vhutsemekers@ulg.ac.be (V. Hutsemékers).
}

number of single-island endemics (Carine and Schaefer, 2010). Recognition as distinct taxa of the genetically distinct entities discovered by molecular analyses drastically change the diversity patterns and make them more similar to those of other Atlantic archipelagos, highlighting that current knowledge of endemic diversity on oceanic islands may be far from complete (Schaefer et al., 2011).

Taxonomic issues in describing and understanding biodiversity patterns are expected to culminate as organisms decrease in size and morphological complexity (Whittaker et al., 2005). In bryophytes, cryptic speciation has been increasingly reported (e.g., Heinrichs et al., 2010; Kreier et al., 2010; Orzechowska et al., 2010; Ramaiya et al., 2010) and might offer an explanation for one of the most striking biogeographic features of bryophytes, that is, the extremely low rates of endemism of their floras (see Vanderpoorten et al., 2010a for review). In Macaronesia for example, a biogeographic region comprised of the mid-Atlantic archipelagos of the Azores, Madeira, and the Canary Islands, and which is recognized as an important floristic area for conservation within the European-Mediterranean climate region (Médail and Quezel, 1997), less than $2 \%$ of species are endemic to the Canarian archipelago, strongly paling in comparison with the $40 \%$ endemism rates observed in angiosperms (Vanderpoorten et al., 2010a). The Macaronesian bryophyte flora is definitely much less well known than its angiosperm 
counterpart, as evidenced by the extremely low levels of completeness of floristic inventories (Aranda et al., 2010) and the continuing finding of new species at a rapid pace (e.g., Dirkse and Losada-Lima, 2011; González-Mancebo et al., 2009). In the liverwort Radula lindenbergiana, which is widespread across Macaronesia, haplotype diversification patterns are comparable to those reported for many angiosperm groups at the species level (Laenen et al., 2011), thereby suggesting that a substantial part of the bryophyte diversity is not paralleled by morphological differentiation.

The resulting increase in the number of new species is, however likely to be counter-balanced by new data from molecular systematics that often lead to extensive synonymizations. In bryophytes, absence of differences at the molecular level often served as evidence in support of synonymization (see Vanderpoorten and Shaw, 2010 for review). A lack of molecular evidence that two species are different never provides, however, definitive evidence that the samples belong to a single species, but rather just fail to provide positive evidence that they are different species. In mosses, standard plant barcodes ( $r b c \mathrm{~L}$ and matK) do globally not perform well, either because of amplification problems (von Crautlein et al., 2011 ), or because of a lack of variation. For instance, a combination of four loci including $r b c \mathrm{~L}$ and matK allowed a species resolution of only 65\% in a set of Chinese Grimmiaceae (Liu et al., 2011). More variable regions of the genome, and nuclear microsatellites in particular, have therefore increasingly been used in moss species-level systematics (e.g., Caruso et al., 2010; Harbaugh et al., 2011; Karlin et al., 2008, 2011; Korpelainen et al., 2008; Peros et al., 2011; Ramaiya et al., 2010).

In this paper, we examine whether the Linnean shortfall may account for the extremely low levels of endemism observed in the Macaronesian bryophyte flora, using the moss Rhynchostegium riparioides as a model. $R$. riparioides was selected because its extremely wide range of morphological variation depending on ecological conditions (Wehr and Whitton, 1986) might potentially reflect actual diversification. This hypothesis is further reinforced by the polyphyletic origin of the species (Huttunen and Ignatov, 2010). Using a range of DNA sequence data and nuclear microsatellite markers, we attempted more specifically at addressing the following questions: (1) Is there evidence for morphologically cryptic diversification of $R$. riparioides in Macaronesia? (2) To what extent does the sharing of ITS sequences among putative species reflect the lack of resolution of this marker or absence of reproductive isolation? (3) Are the diverging lineages within $R$. riparioides truly cryptic and what are the taxonomic consequences of the differentiation of $R$. riparioides across its distribution range?

\section{Material and methods}

\subsection{Taxon sampling, morphological analyses and molecular protocols}

Phylogenetic investigations focused on Rhynchostegium, as recircumscribed by and using the sampling of Huttunen and Ignatov (2010), to which we added the ITS accessions of $R$. riparioides of Wynns et al. (2009), two ITS accessions of Rhynchostegium confertum (Draper and Hedenäs, 2009), five accessions of Rhynchostegium confusum (Cezon et al., 2010) as well as a further 40 new specimens of $R$. riparioides, 10 of Rhynchostegium alopecuroides, and two of Rhynchostegium megapolitanum (Appendix A). These specimens were selected in order to cover the entire distribution range of $R$. riparioides and to represent different genotypes as revealed by the SSR analysis (see below). The sample thus included all the species of the $R$. riparioides complex described to date, namely $R$. riparioides s. str., $R$. alopecuroides, Rhynchostegium mutatum, and Gradsteinia torrenticola. Platyhypnidium muelleri was used as an outgroup based on Huttunen and Ignatov (2010). The new accessions were amplified and sequenced at the two plastid loci (trnL-F and trnDT) and the nuclear region (ITS) employed by Huttunen and Ignatov (2010) and following their protocol. Forward and reverse sequences for each accession were assembled and edited with Sequencher and aligned with BioEdit (Hall, 1999).

Fine-scale analyses were further conducted within and among $R$. ripariodes, $R$. alopecuroides, and $G$. torrenticola. $R$. riparioides was sampled at 77 localities, including 40 from the western Mediterranean (Portugal, Spain, southern France and Morocco); 32 from Macaronesia (Canary Islands; Madeira; and Azores); and five from North America. 91 and 34 sympatric specimens of $R$. riparioides and G. torrenticola were collected at the type (and to date only known) locality of the latter in Tenerife (see online Appendix A). Each of the 1136 gametophytes collected was genotyped at eight microsatellite loci using primers R3, R9, R11, R13 and R17 following the protocols described in Hutsemekers et al. (2008). Another three primer pairs was designed from the library of SSR-enriched loci described in Hutsemekers et al. (2008). These forward and reverse primer pairs are: R21: F: CCCAAATGCAATCCATGA; R: GACGAAGCCGAAACTCGT; R24: F: TCCTCTTGGTTTGAAAAGG; R: GCAGGTGAAATCGAAAGA; R26: F: CGCACTACCGATCTATGC; R: TTTTGCAGTTTCCTCACC.

\subsection{Phylogenetic and population genetic analyses}

The GTR and HKY substitution model were selected for each of the cPDNA and nrDNA partitions based on the Akaike Index Criterion as implemented by JModeltest (Posada, 2008). Indels were scored manually and added to a separate binary character matrix. A model implementing identical forward and backward transition rates was applied to the indel matrix. Independent phylogenetic analyses of each cpDNA and nrDNA datasets were performed in MrBayes 3.1.2 (Ronquist and Huelsenbeck, 2005). For each analysis, four Markov Chain Monte Carlo of 15 million generations were sampled every 10,000 generations. The number of generations needed to reach stationarity and chain convergence was estimated by visual inspection of the plot of the log-likelihood score at each sampling point. The trees from the 'burnin' for each run were excluded from the tree set and the remaining trees from each run were combined to form the full sample of trees assumed to be representative of the posterior probability distribution. No conflict with a posterior probability $>70 \%$ was observed by visual inspection of the $50 \%$ majority-rule consensus trees derived from the separate analysis of the cpDNA and nrDNA datasets, and the two partitions were therefore combined.

To test the monophyly of the North American and European accessions, respectively, the analysis was re-run twice independently under the constraint that only trees compatible with a monophyletic origin of either the North American or European accessions were sampled. The log marginal likelihood returned by each competing model was estimated using the method of Newton and Raftery (1994) with the modifications proposed by Suchard et al. (2001) after 1000 bootstrap replicates. Bayes factors, which correspond to twice the difference of the log marginal likelihoods between constrained and unconstrained analyses, were then used to assess significance of the difference between the two competing models. A threshold value of 2 was taken as positive evidence for selecting one model over another (Raftery, 1996). For the North American specimens, the test was conducted with the ITS partition since only that region was sequenced for the specimens used by Wynns et al. (2009).

The global genetic structure of the microsatellite data was explored by means of a Principal Coordinate Analysis (PCoA) based on a genetic covariance-standardized matrix between each pair of individuals with GenAlex 6 (Peakall and Smouse, 2006). The differentiation among species of the $R$. riparioides complex was 
measured by Fst with Spagedi 1.3 (Hardy and Vekemans, 2002). Significance of Fst was assessed by 1000 allele permutations.

\subsection{Morphological analyses}

A total of 59 specimens, including the type of R. mutatum, Platyhypnidium torrenticola, 14 specimens of Rhynchostegium aquaticum, 11 of $R$. alopecuroides, 17 of $R$. riparioides from North America, and 15 from Europe, Macaronesia and North Africa, were employed in morphometric investigations (Appendix B). Twenty-two characters, including 19 gametophytic and three sporophytic traits, respectively (Appendix C), were selected for their relevance for species circumscriptions (Smith, 2004) or for exhibiting variation (Wynns, 2006; Huttunen and Ignatov, 2010) within the complex. Only six of the investigated specimens bore sporophytes, however, making it impossible to employ the sporophytic traits in the statistical analyses. Characters were scored following the protocol described in Wynns (2006). One specimen was selected at random from each collection, and measurements were performed on five randomly selected leaves. Branch and stem leaves are not dimorphic in the $R$. riparioides complex and all measurements were performed on stem leaves. For cell measurements, one of each cell type was measured on a single leaf. Those traits were scored from the specimens listed in Appendix B, although information for nine specimens of $R$. riparioides from North America and five of $R$. aquaticum was taken from Wynns (2006).

We first explored whether correlated suites of traits allowed to identify distinct phenotypes using a Principal Component Analysis (PCA). Owing to the heterogeneous nature of the variables scored, the analysis was performed on a covariance matrix as implemented by Statistica 10 . We then explored whether the morphological groups of specimens correlated with the phylogeny by performing a regression analysis between the assignation of each specimen to a phylogenetic lineage (i.e., $R$. riparioides from North America, $R$. riparioides from Europe and Africa, $R$. alopecuroides, and $R$. aquaticum) and its score on the two first PCA axes. We subsequently assessed whether informing a priori the analysis with phylogeny would allow for a better morphological circumscription of the species. We therefore conducted a Linear Discriminant Analysis (LDA) to find the combinations of morphological traits that best allow for species identification. In order to remove any bias in the number of sampled specimens per species, prior probabilities of classification were constrained to be equal among species. To avoid multicollinearity, a forward variable selection was implemented, wherein all the variables with a $p$-value $<0.01$ were included in the model. The predictive power of the model was subsequently assessed by cross-validation. For that purpose, 50\% of the specimens were randomly selected and included in a training set that was used to build the model. The latter was then employed to assign each of the specimens of the test set to a species, and the error between the prediction derived from the morphology and the phylogenetic position was measured. A canonical discriminant analysis was finally performed to produce a graphic representation of the specimens along axes that best discriminate the species.

\section{Results}

The nucleotide matrix of trnL-F and trnD-T and ITS within Rhynchostegium contains 130 variable sites ( 44 for trnD-T; 44 for trnL-F and 42 for ITS) and 38 indels. The 50\% majority-rule consensus of the 1483 trees sampled from the posterior probability distribution of the combined analysis is presented in Fig. 1. R. riparioides is resolved as polyphyletic, and constraining all the accessions of the species to monophyly leads to a significant loss of log-likelihood
( marginal $\ln L$ constrained $=-3924.09$, unconstrained $=-3748.63)$. Macaronesian and European accessions of $R$. riparioides form, with G. torrenticola, a clade supported with a posterior probability (hereafter, p.p.) of $94 \%$. The $R$. riparioides clade is sister to a clade, supported with a p.p. of 1.00 , including all the accessions of $R$. alopecuroides, $R$. mutatum, $R$. confertum, $R$. megapolitanum and $R$. confusum. Within that clade, the accession of $R$. confertum and the two accessions of $R$. megapolitanum are basal to the clade formed by $R$. confusum and $R$. alopecuroides, which is weakly supported with a p.p. of 0.63 . Within the latter, all the accessions of $R$. confusum and $R$. alopecuroides are resolved as monophyletic with a p.p. of 0.90 and 0.91 , respectively.

North American accessions of $R$. riparioides are polyphyletic, with an accession from Kentucky resolved as sister to the South American Rhynchostegium sub-rusciforme with a p.p. of 1.00 , whereas all the other North American accessions form a grade at the base of the tree. Constraining this grade to monophyly in the reconstruction based on ITS does not, however, lead to a significant loss in $\log$-likelihood (marginal $\ln L$ constrained $=-1200.52$, unconstrained $=-1200.71$ ).

Microsatellite loci vary considerably in their level of diversity and range from 2 to 23 alleles per locus, with a total of 94 alleles for the 10 microsatellite loci. Along the first axis of the PCoA, which accounts for $36 \%$ of the variance, $R$. alopecuroides and North American accessions of $R$. riparioides exhibit a positive coordinate and are opposed to Macaronesian and European accessions (Fig. 2). Along PCoA2, which accounts for $16 \%$ of the variance, accessions of $R$. alopecuroides exhibit a positive coordinate and are clearly separated from the North American accessions of $R$. riparioides. $R$. alopecuroides and North American accessions of $R$. riparioides are thus clearly differentiated genetically from Mediterranean and Macaronesian accessions, with significantly different allele frequencies (Table 1). In contrast, samples of G. torrenticola share the same alleles as those of Macaronesian and European accessions of $R$. riparioides, from which they are not differentiated in allelic frequency (Table 1).

The matrix of 22 variable morphological characters within the $R$. riparioides complex is provided in Appendix D. The first two PCA axes account for $79.7 \%$ and $20.0 \%$ of the total morphological variance, respectively. PCA1 is a size axis that best correlates with the length of the laminal cells (character \#2, $r=0.41$ ), stem leaf length (character \#8, $r=0.95$ ) and width (character \#9, $r=0.76$ ) and the width of the costa at base (character \#11, $r=0.46$ ). This axis does not contribute to the differentiation among species (Fig. 3), as confirmed by the absence of correlation between this axis and the phylogenetic lineages $(r=0.06, p>0.05)$. Along PCA2, many specimens from different species appear intermixed, but the axis significantly contributes to the differentiation among species $(r=0.43, p<0.001)$. Accessions of $R$. aquaticum tend to exhibit positive coordinates along PCA2 and are opposed to European accessions of $R$. riparioides and $R$. alopecuroides, while North American accessions of $R$. riparioides occupy an intermediate position (Fig. 3). Variation in stem leaf (character $\# 10, r=-0.85$ ) and laminal cell (character $\# 4, r=-0.42$ ) length to width ratio best account for this differentiation.

In the LDA, the discriminant functions allow for a correct classification rate of specimens from their morphological traits of $77 \%$ after cross-validation. The plot of the specimens along the first two canonical discriminant axes, which account for $93 \%$ of the covariance, visually confirms the existence of a morphological differentiation, although accessions of $R$. riparioides from North America and Europe tend to exhibit a continuous range of variation (Fig. 4). The standardized coefficients of the selected variables on the first two axes are presented in Table 2. Axis 1 is mostly loaded with the coloration of the gametophyte, the leaf length to width ratio, the insertion of the leaves on the stem, and the porosity of the 
Platyhypnidium muelleri

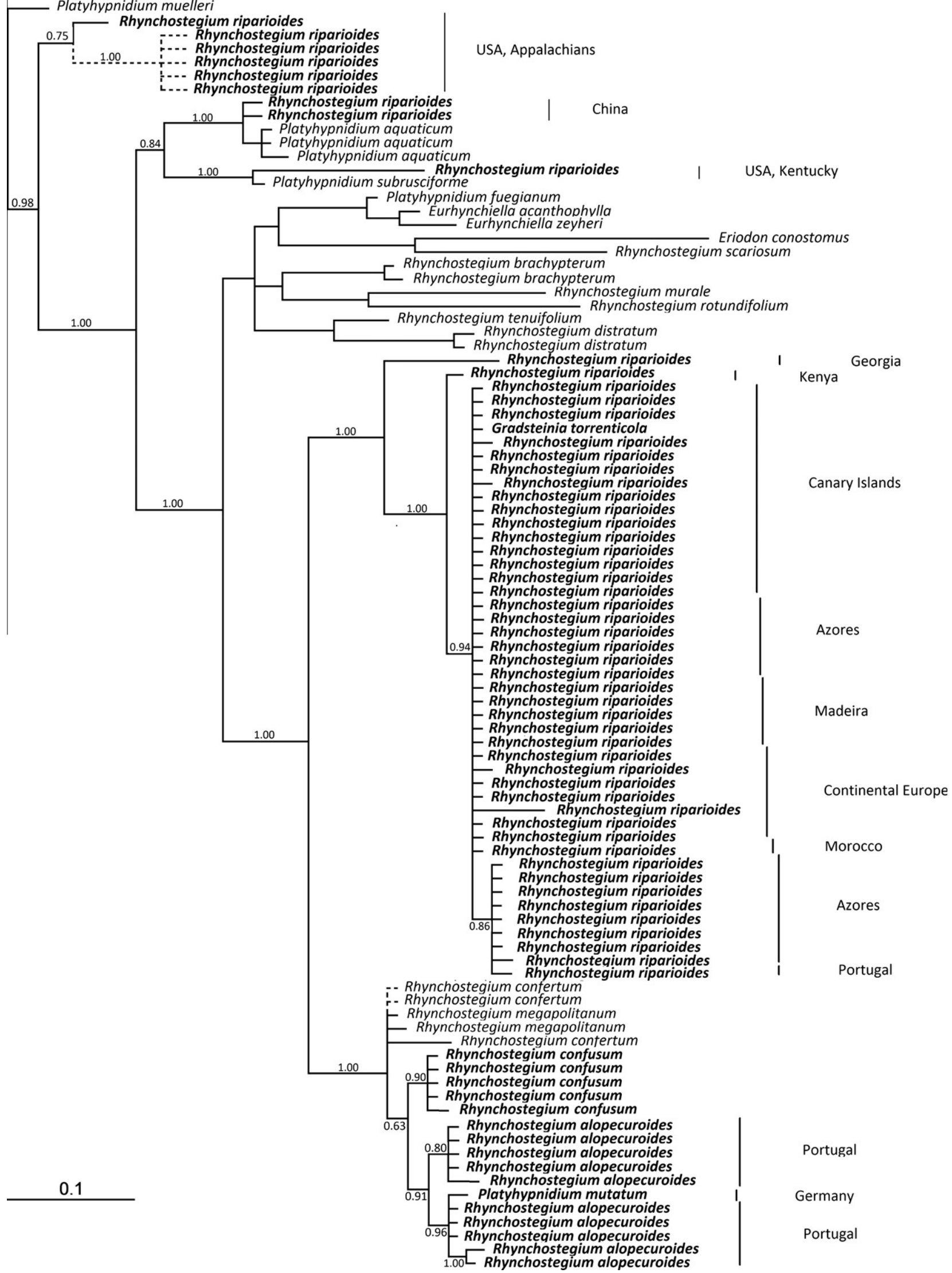

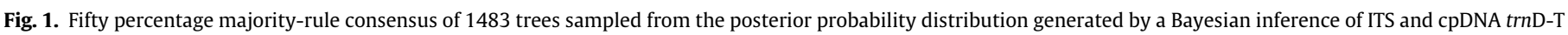
and trnL-F sequence data in the moss genus Rhynchostegium. Dotted lines correspond to the position of accessions based on ITS sequences only. 


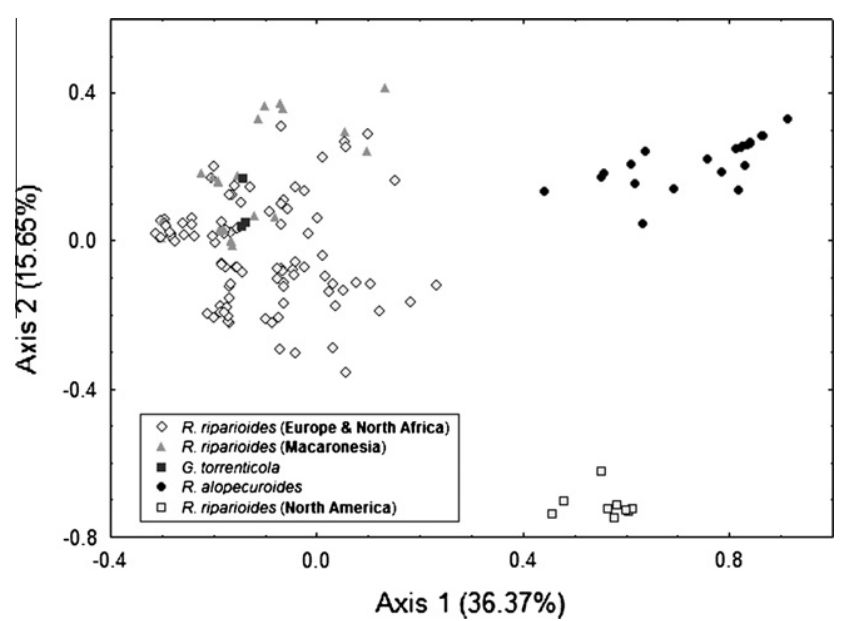

Fig. 2. Principal Coordinate Analysis of allelic variation at eight nuclear microsatellite loci in accessions of the moss Rhynchostegium riparioides from Macaronesia, Europe and North America, $R$. alopecuroides, and Gradsteinia torrenticola.

basal cells; and axis 2 with basal cell length, laminal cell length to width ratio, and stem leaf length. A summary of the differences in state among species for those characters is provided in Table 3.

\section{Discussion}

The deep polyphyly of $R$. riparioides across its distribution range reveals active differentiation. This differentiation is, however, blurred in morphometric analyses by a size gradient that accounts for $80 \%$ of the variation observed among gametophytic traits. This might explain why variation in gametophytic traits in the group was traditionally not thought to warrant taxonomic recognition (Wehr and Whitton, 1986). In $R$. riparioides, like in other groups of aquatic mosses (e.g. Fontinalis, Shaw and Allen, 2000; Sphagnum, Shaw et al., 2005), geography rather than morphology accounts for the patterns of genetic variation observed. Thus the European accessions of $R$. riparioides are resolved as sister to the European endemic $R$. alopecuroides, whereas the North American accessions of $R$. riparioides occur at the opposite side of the phylogeny along with the pantropical $R$. aquaticum. In many instances, incongruence between traditional species concepts and molecular data prompted renewed morphological evaluation, uncovering consistent morphological characters and the description of new species (e.g., Andres-Sanchez et al., 2009; Cezon et al., 2010; Särkinen et al., 2011; Szweykowski et al., 2005; Vanderpoorten et al., 2010b; Zomlefer et al., 2006). In fact, the LDA analysis, which attempts at finding the best combinations of morphological traits to distinguish the molecular lineages, points to the existence of morphological discontinuities among the latter. The global rate of error associated to specimen assignation based on morphology

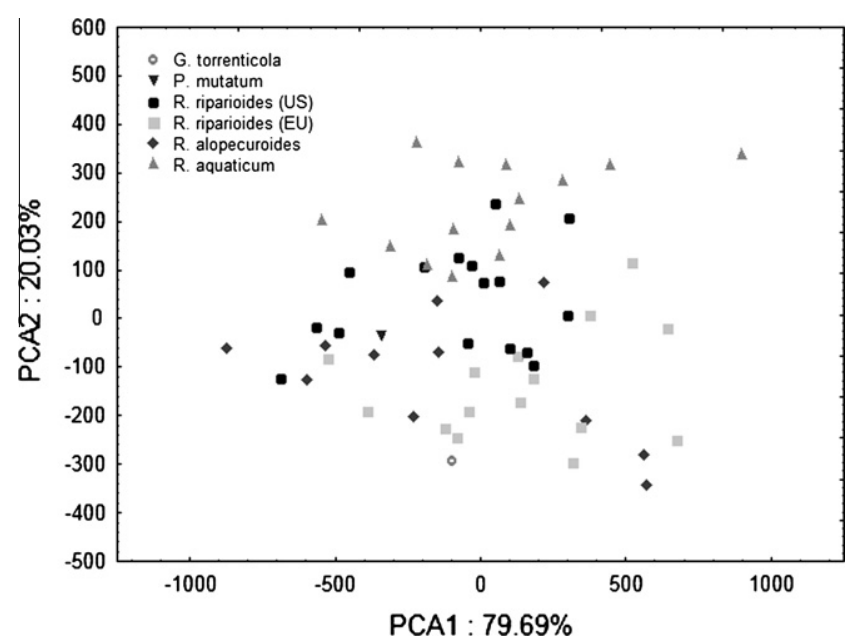

Fig. 3. Plot of 59 specimens of $R$. riparioides from Europe and Africa; North America; $R$. torrenticola; R. aquaticum; R. mutatum; and P. torrenticola along the first two PCA axes derived from the variation at 19 gametophytic traits.

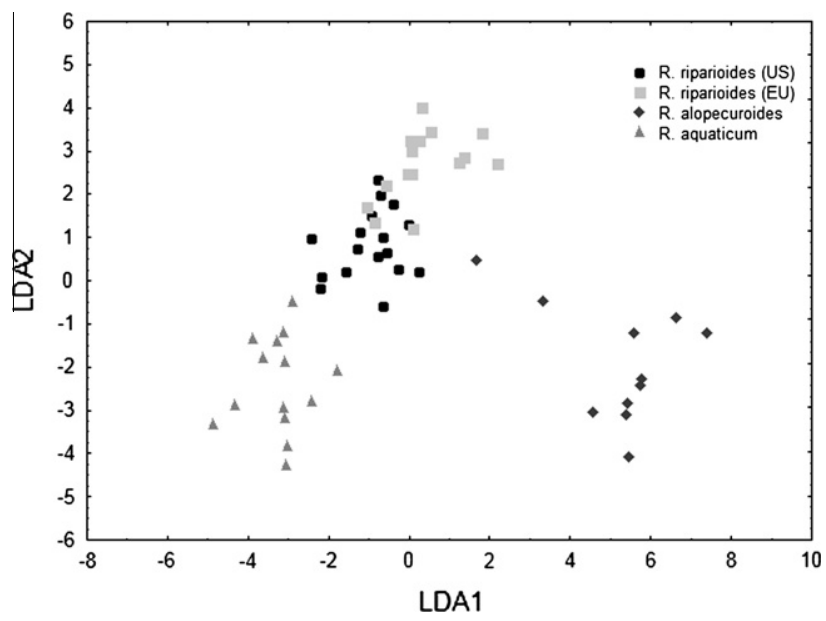

Fig. 4. Plot of 57 specimens of $R$. riparioides from Europe, Africa, and North America $R$. alopecuroides; and $R$. aquaticum along the first two axes of a canonical discriminant analysis of 19 gametophytic traits.

(0.23) indicates, however, that, as in other groups of morphologically similar species (e.g. Leucobryum; Vanderpoorten et al., 2003), intergradation of shape and size characters among species can challenge their identification.

All the accessions of $R$. riparioides in Europe are monophyletic. Sequence data indicate that $R$. riparioides and $R$. alopecuroides belong to distinct and well-supported clades, and significant differences in SSR allele frequencies point to reproductive isolation between the two lineages. Although morphologically intermediate

Table 1

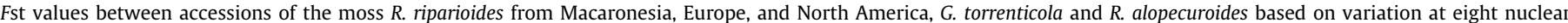
microsatellite loci. NS, ${ }^{* *}{ }^{* * *}: p>0.05,0.01$; and 0.001 , respectively.

\begin{tabular}{|c|c|c|c|c|c|c|}
\hline & & \multicolumn{3}{|l|}{ R. riparioides } & \multirow[t]{2}{*}{ G. torrenticola } & \multirow[t]{2}{*}{ R. alopecuroides } \\
\hline & & Macaronesia & Southwestern Mediterranean & North America & & \\
\hline R. riparioides & $\begin{array}{l}\text { Macaronesia } \\
\text { Southwestern Mediterranean } \\
\text { North America }\end{array}$ & 0 & $\begin{array}{l}0.13^{* * *} \\
0\end{array}$ & $\begin{array}{l}0.54^{* * *} \\
0.45^{* * *} \\
0\end{array}$ & $\begin{array}{l}\text { NS } \\
\text { NS } \\
0.08^{* * *}\end{array}$ & $\begin{array}{l}0.62^{* * *} \\
0.43^{* * *} \\
0.25^{* *}\end{array}$ \\
\hline $\begin{array}{l}\text { G. torrenticola } \\
\text { R. alopecuroides }\end{array}$ & & & & & 0 & $\begin{array}{l}0.33^{* * *} \\
0\end{array}$ \\
\hline
\end{tabular}


Table 2

Standardized coefficients of the selected morphological variables in the canonical discriminant analysis.

\begin{tabular}{rrr}
\hline Variable & Comp_1 & Comp_2 \\
\hline 1 & 0.574 & -0.411 \\
10 & 0.330 & 0.401 \\
5 & -0.198 & -0.398 \\
11 & -0.055 & 0.272 \\
19 & -0.158 & -0.306 \\
14 & -0.430 & 0.090 \\
7 & -0.066 & 0.229 \\
4 & 0.147 & 0.216 \\
16 & 0.007 & 0.156 \\
8 & 0.028 & 0.138 \\
15 & 0.029 & -0.019 \\
6 & -0.166 & -0.111 \\
\hline
\end{tabular}

specimens occur, explaining why the two species have sometimes been synonymized (Köckinger et al., 2011), the analyses presented here thus support the recognition of $R$. alopecuroides as a distinct species. As opposed to previous treatments that emphasized differences in the width of the lamina cells (e.g. Smith, 2004), this character did not allow to distinguish accessions from the two species. Rather, accessions of $R$. alopecuroides were characterized by the brownish color of the gametophyte and concave leaves appressed to the stem, giving a julaceous appearance to the latter.

In North America, specimens previously assigned to $R$. riparioides are polyphyletic. One accession from Kentucky was resolved within the $R$. aquaticum clade, while the remainder was resolved at the base of the phylogeny, at the opposite of Macaronesian and European accessions. The Kentucky accession exhibits the typical $R$. aquaticum morphology, with rounded leaves characterized by a length to width ratio of less than 1.3 and a laminal cell length to width ratio of $<10$. Differences in sporophytic features, and especially spore size, could not be characterized owing to the minimal number of fertile specimens investigated here, but were not reported in Wynn's (2006) monograph. The presence of $R$. aquaticum in Kentucky can be interpreted as an event of irradiation of the Neotropical flora into North America, a process that is well documented for other bryophyte (Schofield and Crum, 1972) and angiosperm (Wood, 1972) species disjunct between the Appalachian valleys and the Neotropics. From the specimens surveyed in this study, it appears, however, that R. aquaticum is rare in North America. In fact, the bulk of North American accessions forms, as opposed to the view, that they all belong to R. aquaticum (Ignatov, 2009), a distinct and well-supported clade at the basis of the phylogeny. The accessions of this clade are further characterized by substantial and significant differences in SSR allele frequencies with both $R$. aquaticum and Eurasian accessions. Constraining accessions from this clade to monophyly with either accessions of $R$. aquaticum of European accessions of $R$. riparioides leads to a significant decrease in log-likelihood, confirming their genetic distinctiveness. Morphologically, the characterization of the North American accessions is much more challenging. The differences revealed by the discriminant analysis deal with subtle combinations of continuous traits rather than a sharp distinction in discrete features. North American accessions tend to exhibit more spreading and comparatively shorter and broader leaves, with a leaf length to width ratio of 1.6 vs. 1.9, than European accessions.

The Linnean shortfall might thus explain, at least to some extent, the low levels of endemism in the bryophyte floras worldwide. In the case of the North Atlantic disjunction, $70 \%$ of the European moss species, but only $6.5 \%$ of the vascular plants, are shared with North America (Frahm and Vitt, 1993; Qian, 1999). While the data presented here do not challenge the idea that such differences are due to differences in dispersal ability between bryophytes and angiosperms, they do, however, suggest that those differences are likely to have been over-emphasized owing to a taxonomic artefact.

Despite evidence for active differentiation of $R$. riparioides across its distribution range, the Macaronesian accessions were characterized by a complete absence of private alleles at the investigated nuclear SSR loci and an extremely weak differentiation with continental populations. Although haplotype diversification exhibited by the liverwort $R$. lindenbergiana in Macaronesia is comparable to that reported for many angiosperm groups at the species level (Laenen et al., 2011), $R$. riparioides failed to locally diversify in Macaronesia. This results parallels previous observations of the sharing of alleles among Macaronesian and Mediterranean accessions in the mosses Leucodon sciuroides (Stech et al., 2011), Grimmia montana (Vanderpoorten et al., 2008) and Kindbergia praelonga (Hedenäs, 2010). Altogether, these observations weaken the idea, that the low rates of endemism observed in the Macaronesian bryophyte flora might, as has been for instance evoked in the Azorean angiosperm flora (Schaefer et al., 2011), be explained by the Linnean shortfall. The absence of genetic differentiation between sympatric $R$. riparioides and the Canarian endemic G. torrenticola further suggests that, despite a strikingly different morphology, the two species are not reproductively isolated, and should hence be reduced into synonymy (Werner et al., 2007).

\subsection{Taxonomic consequences}

According to the synonymy in Crum and Anderson's (1981) Mosses of Eastern North America, the only available name for a North American endemic species of the $R$. riparioides complex is Hygrohypnum nicholsii. Grout's (1935) description, however, pictures rounded-obtuse leaves that rather fit with $R$. aquaticum. We are therefore pleased to name the new species Rhynchostegium shawii as a tribute to Jon and Blanka Shaw for their outstanding contribution to bryology:

R. shawii Hutsemekers and Vanderpoorten, spec. nov. Type: Hutsemekers s.n., Chattooga River, near Highlands, North Carolina, USA (Duke, holotype).

Endemic species from North America, differing from $R$. aquaticum by a leaf length to width ratio $>1.3$ and from $R$. riparioides by more spreading, shorter and broader leaves.

Table 3

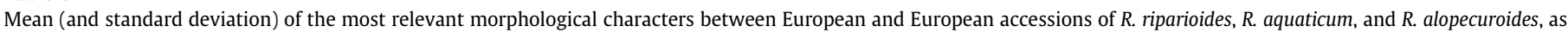
revealed by the discriminant analysis of their morphological variation. See Appendix D for character scoring.

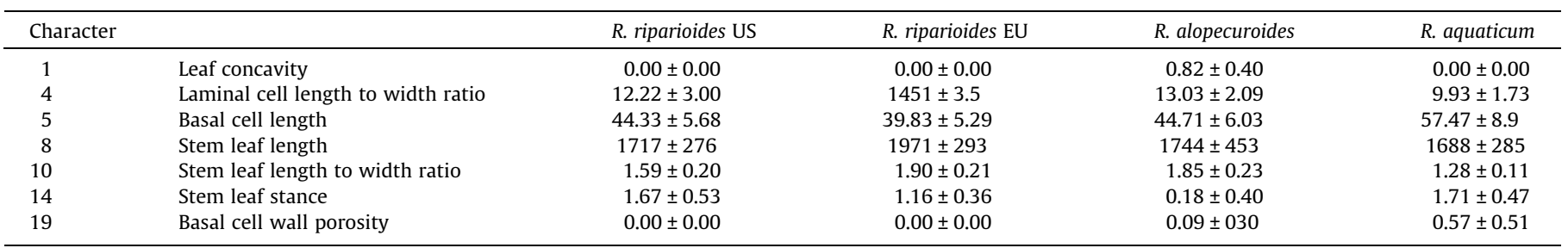




\section{Acknowledgments}

Many thanks are due to the curators of DUKE, BR, NY, and S for the loan of specimens and to P. Rasmont, A. Losada Lima, and J.M. González-Mancebo for their help in the field. Many thanks also to S. Blake Boles and L. Bukovnik for laboratory assistance. This research was funded by Grants 1.5036.11 and 2.4557.11 from the Belgian Funds for Scientific Research (FRS-FNRS), Grant C 11/32 from the University of Liège, as well as a fellowship of the Fonds Léopold III. Many thanks are also due to two referees for their constructive comments on the manuscript.

\section{Appendix A. Supplementary material}

Supplementary data associated with this article can be found, in the online version, at doi:10.1016/j.ympev.2011.11.014.

\section{References}

Andres-Sanchez, S., Rico, E., Herrero, A., Santos-Vicente, M., Martinez-Ortega, M.M., 2009. Combining traditional morphometrics and molecular markers in cryptic taxa: towards an updated integrative taxonomic treatment for Veronica subgenus Pentasepalae (Plantaginaceae sensu APG II) in the western Mediterranean. Bot. J. Linn. Soc. 159, 68-87.

Aranda, S.C., Gabriel, R., Borges, P.A.V., Lobo, J.M., 2010. Assessing the completeness of bryophytes inventories: an oceanic island as a case study (Terceira, Azorean archipelago). Biodiversity Conserv. 19, 2469-2484.

Bickford, D., Lohman, D.J., Sodhi, N.S., Ng, P.K.L., Meier, R., Winker, K., Ingram, K.K., Das, I., 2007. Cryptic species as a window on diversity and conservation. Trends Ecol. Evol. 22, 148-155.

Brown, J.H., Lomolino, M.V., 1998. Biogeography, second ed. Sinauer Press, Sunderland, Massachusetts.

Carine, M.A., Schaefer, H., 2010. The Azores diversity enigma: why are there so few Azorean endemic flowering plants and why are they so widespread? J. Biogeogr. 37, 77-89.

Caruso, M., Curro, S., Casas, G.L., La Malfa, S., Gentile, A., 2010. Microsatellite markers help to assess genetic diversity among Opuntia ficus indica cultivated genotypes and their relation with related species. Plant Syst. Evol. 290, 85-95.

Cezon, K., Muñoz, J., Hedenäs, L., Huttunen, S., 2010. Rhynchostegium confusum, a new species from the Iberian Peninsula and its relations to $R$. confertum based on morphological and molecular data. J. Bryol. 32, 1-8.

Crum, H.A., Anderson, L.E., 1981. Mosses of Eastern North America, vol. 2. Columbia University Press, New York.

Dirkse, G.M., Losada-Lima, A., 2011. Additions and amendments to the moss flora of the Canary Islands. Cryptogamie Bryol. 32, 37-41.

Draper, I., Hedenäs, L., 2009. Circumscription of European taxa within the Sciurohypnum reflexum complex (Brachytheciaceae, Bryophyta), based on molecular and morphological data. Taxon 58, 572-584.

Egge, J.J.D., Simons, A.M., 2006. The challenge of truly cryptic diversity: diagnosis and description of a new madtom catfish (Ictaluridae: Noturus). Zool. Scr. 35, 581-595.

Frahm, J.P., Vitt, D.H., 1993. Comparisons between the moss floras of North America and Europe. Nova Hedwigia 56, 307-333.

González-Mancebo, J.M., Draper, I., Lara, F., Marrero, J.D., Muñoz, J., Patiño, J., Romaguera, F., Vanderpoorten, A., 2009. Amendments to the bryophyte flora of the Cape Verde and Canary Islands. Cryptogamie Bryol. 30, 433-441.

Grout, A.J., 1935. Hygrohypnum nicholsii n. sp. Bryologist 38, 10.

Hall, T.A., 1999. BioEdit: a user-friendly biological sequence alignment editor and analysis program for Windows 95/98/NT. Nucl. Acids Symp. Ser. 41, 95-98.

Harbaugh, D.T., Oppenheimer, H.L., Wood, K.R., Wagner, W.L., 2011. Taxonomic revision of the endangered Hawaiian red-flowered sandalwoods (Santalum) and discovery of an ancient hybrid species. Syst. Bot. 35, 827-838.

Hardy, O.J., Vekemans, X., 2002. SPAGEDI: a versatile computer program to analyse spatial genetic structure at the individual or population levels. Mol. Ecol. Notes 2, 618-620.

Harper, J.T., Gile, G.H., James, E.R., Carpenter, K.J., Keeling, P.J., 2009. The inadequacy of morphology for species and genus delineation in microbial eukaryotes: an example from the parabasalian termite symbiont Coronympha. PLoS ONE, e6577.

Hedenäs, L., 2010. Global relationships and European phylogeography in the Kindbergia praelonga complex (Brachytheciaceae, Bryophyta). Trop. Bryol. 31, 81-90.

Heinrichs, J., Hentschel, J., Bombosch, A., Fiebig, A., Reise, J., Edelmann, M., Kreier, H.P., Schäfer-Verwimp, A., Caspari, S., Schmidt, A.R., Zhu, R.L., von Konrat, M., Shaw, B., Shaw, A.J., 2010. One species or at least eight? Delimitation and distribution of Frullania tamarisci (L.) Dumort. s. 1. (Jungermanniopsida, Porellales) inferred from nuclear and chloroplast DNA markers. Mol. Phylogen. Evol. 56, 1105-1114.

Hutsemekers, V., Risterucci, A.M., Ricca, M., Boles, S., Hardy, O.J., Shaw, A.J., Vanderpoorten, A., 2008. Identification and characterization of nuclear microsatellite loci in the aquatic moss Platyhypnidium. Mol. Ecol. Res. 8, 1130-1132.

Huttunen, S., Ignatov, M.S., 2010. Evolution and taxonomy of aquatic species in the genus Rhynchostegium (Brachytheciaceae, Bryophyta). Taxon 59, 791-808.

Ignatov, M.S., 2009. Rhynchostegium. In: Bryophyte Flora of North America, Provisional Publication. <http://www.mobot.org/plantscience/BFNA/bfnamenu. htm>.

Karlin, E.F., Boles, S.B., Shaw, A.J., 2008. Resolving boundaries between species in Sphagnum section Subsecunda using microsatellite markers. Taxon 57, 11891200.

Karlin, E.F., Boles, S.B., Seppelt, R.D., Terracciano, S., Shaw, A.J., 2011. The peat moss Sphagnum cuspidatum in Australia: microsatellites provide a global perspective. Syst. Bot. 36, 22-32.

Köckinger, H., Schröck, C., Krisai, R., Zechmeister, H.G., 2011. Checklist of Austrian Bryophytes. <http://131.130.59.133/projekte/moose/\#P>.

Korpelainen, H., Virtanen, V., Kostamo, K., Karttunen, H., 2008. Molecular evidence shows that the moss Rhytidiadelphus subpinnatus (Hylocomiaceae) is clearly distinct from R. Squarrosus. Mol. Phylogen. Evol. 48, 372-376.

Kreier, H.P., Feldberg, K., Mahr, F., Bombosch, A., Schmidt, A.R., Zhu, R.L., von Konrat, M., Shaw, B., Shaw, A.J., Heinrichs, J., 2010. Phylogeny of the leafy liverwort Ptilidium: cryptic speciation and shared haplotypes between the Northern and Southern Hemispheres. Mol. Phylogen. Evol. 57, 1260-1267.

Laenen, B., Désamoré, A., Devos, N., Shaw, A.J., González-Mancebo, J.M., Carine, M.A. Vanderpoorten, A., 2011. Macaronesia: a source of hidden genetic diversity for post-glacial recolonization of western Europe in the leafy liverwort Radula lindenbergiana. J. Biogeogr. 38, 631-639.

Liu, Y., Cao, T., Ge, X.J., 2011. A case study of DNA barcoding in Chinese Grimmiaceae and a moss recorded in China for the first time. Taxon 60, 185-193.

Médail, F., Quezel, P., 1997. Hot-spots analysis for conservation of plant biodiversity in the Mediterranean basin. Ann. Missouri Bot. Gard. 84, 112-127.

Newton, M.A., Raftery, A.E., 1994. Approximate Bayesian-inference with the weighted likelihood bootstrap. J. Roy. Stat. Soc. 56, 3-48.

Oliver, P.M., Lee, M.S.Y., 2010. The botanical and zoological codes impede biodiversity research by discouraging publication of unnamed new species. Taxon 59, 1201-1205.

Orzechowska, M., Siwinska, D., Maluszynska, J., 2010. Molecular cytogenetic analyses of haploid and allopolyploid Pellia species. J. Bryol. 32, 113-121.

Pavlic, D., Slippers, B., Coutinho, T.A., Wingfield, M.J., 2009. Multiple gene genealogies and phenotypic data reveal cryptic species of the Botryosphaeriaceae: a case study on the Neofusicoccum parvum/N. Ribis complex. Mol. Phylogen. Evol. 51, 259-268.

Peakall, R., Smouse, P.E., 2006. GENALEX 6: genetic analysis in Excel. Population genetic software for teaching and research. Mol. Ecol. Notes 6, 288-295.

Peros, J.P., Berger, G., Portemont, A., Boursiquot, J.M., Lacombe, T., 2011. Genetic variation and biogeography of the disjunct Vitis subg. Vitis (Vitaceae). J. Biogeogr. 38, 471-486.

Posada, D., 2008. jModelTest: phylogenetic model averaging. Mol. Biol. Evol. 25 1253-1256.

Qian, H., 1999. Spatial pattern of vascular plant diversity in North America North of Mexico and its floristic relationships with Eurasia. Ann. Bot. 83, 271-283.

Raftery, A.E., 1996. Approximate Bayes factors and accounting for model uncertainty in generalized linear models. Biometrika 183, 251-266.

Ramaiya, M., Johnson, M., Shaw, B., Heinrichs, J., Hentschel, J., von Konrat, M., Davison, P., Shaw, A.J., 2010. Morphologically cryptic biological species within the liverwort, Frullania asagrayana. Am. J. Bot. 10, 1707-1718.

Ronquist, F., Huelsenbeck, J.P., 2005. MrBayes 3: Bayesian phylogenetic inference under miwed models. Bioinformatics 19, 1572-1574.

Samson, R.A., Varga, J., 2009. What is a species of Aspergillus? Med. Mycol. 47, 13-20.

Särkinen, T.E., Marcelo-Peña, J.L., Daza Yomona, A., Simon, M.F., Pennington, R.T., Hughes, C.E., 2011. Underestimated endemic species diversity in the dry interAndea valley of Río Marañón, northern Peru: an example from Mimosa (Leguminosae, Mimosoideae). Taxon 60, 139-150.

Schaefer, H., Moura, M., Graciete Belo Maciel, M., Silva, L., Rumsey, F.J., Carine, M.A. 2011. The Linnean shortfall in oceanic island biogeography: a case study in the Azores. J. Biogeogr. 38, 1345-1355.

Schofield, W.B., Crum, H.A., 1972. Disjunctions in bryophytes. Ann. Missouri Bot Gard. 59, 174-202.

Shaw, A.J., Allen, B., 2000. Phylogenetic relationships, morphological incongruence, and geographic speciation in the Fontinalaceae (Bryophyta). Mol. Phylogen. Evol. 16, 225-237.

Shaw, A.J., Melosik, I., Cox, C.J., Boles, S.B., 2005. Divergent and reticulate evolution in closely related species of Sphagnum section Subsecunda. Bryologist 108, 363-376.

Smith, A.J.E., 2004. The moss flora of Britain and Ireland, second ed. Cambridge University Press, Cambridge.

Stech, M., Werner, O., González-Mancebo, J.M., Patiño, J., Sim-Sim, M., Fontinha, S., Hildebrandt, I., Ros, R.M., 2011. Phylogenetic inference in Leucodon Schwägr. Subg. Leucodon (Leucodontaceae, Bryophyta) in the North Atlantic region. Taxon 60, 79-88.

Suchard, M.A., Weiss, R.E., Sinsheimer, J.S., 2001. Bayesian selection of continuoustime Markov chain evolutionary models. Mol. Biol. Evol. 18, 1001-1013.

Szweykowski, J., Buczkowska, K., Odrzykoski, I.J., 2005. Conocephalum salebrosum (Marchantiopsida, Conocephalaceae) - a new Holarctic liverwort species. Plant Syst. Evol. 253, 133-154.

Vanderpoorten, A., Shaw, A.J., 2010. The application of molecular data to the phylogenetic delimitation of species in bryophytes: a note of caution. Phytotaxa 9, 229-237. 
Vanderpoorten, A., Boles, S., Shaw, A.J., 2003. Patterns of molecular and morphological variation in Leucobryum albidum, $L$. glaucum, and $L$. juniperoideum (Bryopsida). Syst. Bot. 28, 651-656.

Vanderpoorten, A., Devos, N., Goffinet, B., Hardy, O.J., Shaw, A.J., 2008. The barriers to oceanic island radiation in bryophytes: insights from the phylogeography of the moss Grimmia montana. J. Biogeogr. 35, 654-663.

Vanderpoorten, A., Gradstein, S.R., Devos, N., Carine, M.A., 2010a. The ghosts of Gondwana and Laurasia in modern liverwort distributions. Biol. Rev. 85, 471-487.

Vanderpoorten, A., Schäfer-Verwimp, A., Heinrichs, J., Devos, N., Long, D.G., 2010b. The taxonomy of the leafy liverwort genus Leptoscyphus (Lophocoleaceae) revisited. Taxon 59, 176-186.

von Crautlein, M., Korpelainen, H., Pietilainen, M., Rikkinen, J., 2011. DNA barcoding: a tool for improved taxon identification and detection of species diversity. Biodivers. Conserv. 20, 373-389.

Wehr, J.D., Whitton, B.A., 1986. Ecological factors relating to morphologica variation in the aquatic moss Rhynchostegium riparioides (Hedw) C Jens. J. Bryol. 14, 269-280.
Werner, O., Patiño, J., González-Mancebo, J.M., Ros, R.M., 2007. The status of Platyhypnidium torrenticola based on ITS sequence data. Cryptogamie Bryol. 28, 187-195.

Whittaker, R.J., Araújo, M.B., Paul, J., Ladle, R.J., Watson, J.E.M., Willis, K.J., 2005. Conservation biogeography: assessment and prospect. Divers. Distrib. 11, 3-23.

Wilson, E.O., 2003. The encyclopedia of life. Trends Ecol. Evol. 18, 77-80.

Wood, C.E., 1972. Morphology and phytogeography: the classical approach to the study of disjunctions. Ann. Missouri Bot. Gard. 59, 107-124.

Wynns, J., 2006. Taxonomic studies in the aquatic moss genus Platyhypnidium (Brachytheciaceae). Msc thesis, Appalachian State University.

Wynns, J.T., Keith, J.N., Murrel, Z.E., McFarland, K.D., Buck, W.R., 2009. Studies on aquatic Oxyrrhynchium (Brachytheciaceae), with an emphasis on O. Pringlei $\mathrm{n}$. comb. Bryologist 112, 786-803.

Zomlefer, W.B., Whitten, W.M., Williams, N.H., Judd, W.S., 2006. Infrageneric phylogeny of Schoenocaulon (Liliales: Melanthiaceae) with clarification of cryptic species based on ITS sequence data and phylogeographical distribution. Am. J. Bot. 93, 1178-1192. 